\title{
Host Calcium Channels and Pumps in Viral Infections
}

\author{
Xingjuan Chen ${ }^{1,2}$, Ruiyuan Cao ${ }^{2, *}$ and Wu Zhong ${ }^{2, *(D)}$ \\ 1 Institute of Medical Research, Northwestern Polytechnical University, Xi'an 710072, China; \\ xjchen@nwpu.edu.cn \\ 2 National Engineering Research Center for the Emergency Drug, Beijing Institute of Pharmacology and \\ Toxicology, Beijing 100850, China \\ * Correspondence: 21cc@163.com (R.C.); zhongwu@bmi.ac.cn (W.Z.)
}

Received: 11 December 2019; Accepted: 24 December 2019; Published: 30 December 2019

check for updates

\begin{abstract}
Ca}^{2+}$ is essential for virus entry, viral gene replication, virion maturation, and release. The alteration of host cells $\mathrm{Ca}^{2+}$ homeostasis is one of the strategies that viruses use to modulate host cells signal transduction mechanisms in their favor. Host calcium-permeable channels and pumps (including voltage-gated calcium channels, store-operated channels, receptor-operated channels, transient receptor potential ion channels, and $\mathrm{Ca}^{2+}$-ATPase) mediate $\mathrm{Ca}^{2+}$ across the plasma membrane or subcellular organelles, modulating intracellular free $\mathrm{Ca}^{2+}$. Therefore, these $\mathrm{Ca}^{2+}$ channels or pumps present important aspects of viral pathogenesis and virus-host interaction. It has been reported that viruses hijack host calcium channels or pumps, disturbing the cellular homeostatic balance of $\mathrm{Ca}^{2+}$. Such a disturbance benefits virus lifecycles while inducing host cells' morbidity. Evidence has emerged that pharmacologically targeting the calcium channel or calcium release from the endoplasmic reticulum (ER) can obstruct virus lifecycles. Impeding virus-induced abnormal intracellular $\mathrm{Ca}^{2+}$ homeostasis is becoming a useful strategy in the development of potent antiviral drugs. In this present review, the recent identified cellular calcium channels and pumps as targets for virus attack are emphasized.
\end{abstract}

Keywords: virus; calcium channels; calcium pumps; virus-host interaction; antiviral

\section{Introduction}

Viruses exploit the environment of host cells to replicate, thereby inducing host cells' dysfunction. Virus-host interaction is the foundation of pathogenesis and closely associated with disease severity and incidence. The prevention and therapy of virus infections are often confounded by the high mutation rates that facilitate the viral evasion of antiviral strategies that target virally encoded proteins. Modulations of the intracellular environment have become an important strategy in antiviral drug discovery and development. In mammalian cells, $\mathrm{Ca}^{2+}$, as an important second messenger, mediates the sensor input and responses output for almost all known cellular progress, such as stress responses, synaptic plasticity, immunodefenses, protein transport, and endosome formation [1,2]. It has been demonstrated that the host cell dysfunction following infection with a virus is accompanied by abnormal intracellular $\mathrm{Ca}^{2+}$ concentration [3]. A virus can hijack the host intracellular $\mathrm{Ca}^{2+}$ system to achieve successful replication via multiple routes; for instance, viral proteins directly bind to $\mathrm{Ca}^{2+}$ or disturb the membrane permeability for $\mathrm{Ca}^{2+}$ by manipulating $\mathrm{Ca}^{2+}$ apparatus.

The host cell plasma membrane is the first barrier against the invasion of viruses. Various $\mathrm{Ca}^{2+}$ channels and pumps are distributed on the cell plasma membrane. Therefore, these membrane proteins become the direct target of virus infection. Interaction between viruses and these membrane proteins is the foremost approach of viruses perturbing the host cell calcium signal system. This interaction may inhibit or stimulate calcium influx and modulate free cytosolic $\mathrm{Ca}^{2+}$ concentrations. After entry 
into the host cell, viruses stimulate or inhibit the calcium release from internal stores via an effect on calcium-permeable channels, transporters, and exchangers on organellar membranes. Then, the change in cytosolic calcium concentration may trigger further distortion of the host cell system, which benefits virus survival and replication.

This review concentrates on host cell membranes' calcium channels and pumps in viral infection. Blockers for these membrane proteins or preventing viruses from grabbing these host calcium-signaling components may lower the probability of virus stability, replication, and release, as well as infection-related host-cell apoptosis and reactive oxygen species production, neurotoxicity, and enterotoxin, making these membrane proteins potential targets for antiviral drugs.

\section{Calcium Channels and Pumps in Host $\mathrm{Ca}^{2+}$ Homeostasis}

Cellular $\mathrm{Ca}^{2+}$ is from two major sources: the internal $\mathrm{Ca}^{2+}$ store (mainly endoplasmic reticulum (ER) or sarcoplasmic reticulum (SR)) and the extracellular medium. Calcium channels on cell plasma membrane mediate the entry of $\mathrm{Ca}^{2+}$ from the extracellular medium. These channels are activated by specific stimuli, such as voltage-gated calcium channels (VGCCs), which are stimulated by membrane depolarization, specific receptor-operated channels (ROC), which are stimulated by external agonists, or intracellular messengers and store-operated calcium channel (SOC), which are stimulated by the depletion of internal $\mathrm{Ca}^{2+}$ stores. The $\mathrm{IP}_{3}$ receptor $\left(\mathrm{IP}_{3} \mathrm{R}\right)$ and the ryanodine receptors $(\mathrm{RyR})$ are the main players in mediating the release of $\mathrm{Ca}^{2+}$ from the internal stores. Inositol-1,4,5-triphosphate $\left(\mathrm{IP}_{3}\right)$ activates $\mathrm{IP}_{3} \mathrm{R}$, triggers $\mathrm{Ca}^{2+}$ release from stores, and further increases $\mathrm{IP}_{3} \mathrm{R}^{\prime}$ s sensitivity to $\mathrm{Ca}^{2+}$. Calcium pumps (the plasma membrane $\mathrm{Ca}^{2+}$-ATPase (PMCA), sarcoplasmic/endoplasmic reticulum $\mathrm{Ca}^{2+}$-ATPase (SERCA)) and the $\mathrm{Na}^{+} / \mathrm{Ca}^{2+}$ exchanger (NCX) are responsible for transporting $\mathrm{Ca}^{2+}$ from the cytosol to external medium or into cellular calcium stores (Figure 1). The normal function of these calcium channels and pump is important for cells to maintain intracellular $\mathrm{Ca}^{2+}$ homeostasis.

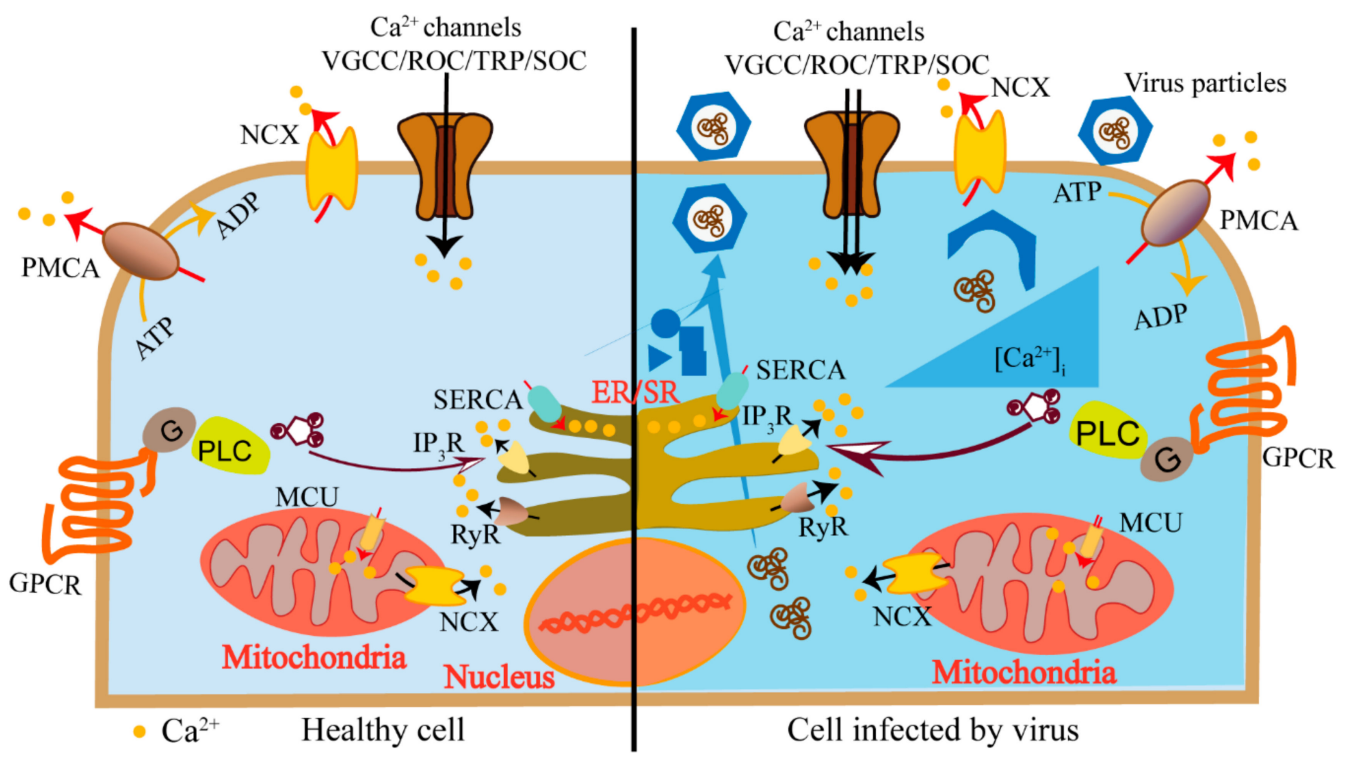

Figure 1. Schematics of host cell elevated cytosolic calcium concentration induced by a virus. Calcium channels (voltage-gated calcium channels (VGCCs), receptor-operated channels (ROC), store-operated $\mathrm{Ca}^{2+}$ (SOC), channels and transient receptor potential (TRP) channels) mediate the entry of $\mathrm{Ca}^{2+}$ from extracellular medium (black arrows). The $\mathrm{IP}_{3}$ receptor $\left(\mathrm{IP}_{3} \mathrm{R}\right)$ and the ryanodine receptors (RyR) on the endoplasmic reticulum (ER) mediate the release of $\mathrm{Ca}^{2+}$ from internal stores (black arrows). Calcium pumps (the plasma membrane $\mathrm{Ca}^{2+}$-ATPase (PMCA), sarcoplasmic/endoplasmic reticulum $\mathrm{Ca}^{2+}$-ATPase (SERCA)) and the $\mathrm{Na}^{+} / \mathrm{Ca}^{2+}$ exchanger (NCX) are responsible for transporting $\mathrm{Ca}^{2+}$ from the cytosol to external medium or into cellular calcium stores (red arrows). Viruses utilize these calcium components to elevate cytosolic calcium concentration to activate $\mathrm{Ca}^{2+}$-dependent/sensitive enzymes and transcriptional factors to promote virus replication (right panel). 
These channels and pumps are activated in a flexible and precise manner to generate specific $\mathrm{Ca}^{2+}$ signaling, satisfying various spatiotemporal requirements. During the viral infections, host cells modulate these calcium-signaling components in response to the infection. On the other hand, viruses utilize these components to create a cellular environment that benefits their own lifecycles [4]. Viruses induce elevated cytosolic calcium concentration to activate $\mathrm{Ca}^{2+}$ dependent/sensitive enzymes and transcriptional factors to promote virus replication. Mitochondria could take the $\mathrm{Ca}^{2+}$ to generate more energy to support continuous virus replication. Moreover, regulating the calcium concentration in ER or Golgi may inhibit host proteins trafficking and promote virus protein maturation. The inhibition of host proteins frustrates host antiviral immune responses, while the promotion of virus protein maturation benefits virus propagation (Figure 1). The journey begins when a virus encounters the host cell and attaches to the cell surface. The virus particle penetrates the cytoplasm via direct membrane fusion or receptor-mediated endocytosis followed by exposing its genome to cellular machinery for replication. When the viral proteins and viral genomes are accumulated, they are assembled to form a progeny virion particle and then released [5]. During the viral lifecycles, they utilize various calcium channels and pumps to obviate the cell membrane barriers, enter the host cell, complete replication, acquire infection ability, and release.

\section{Viruses Control Host Voltage-Gated Calcium Channels (VGCCs) and Two-Pore Channels (TPCs)}

VGCCs are widely found in the membrane of excitable cells [6] and one of the most well studied viral targets because of the availability of specific channel blockers. There are several different types of VGCCs: L-type (Long-conducting) channels are mostly found in skeletal and smooth myocytes, bone (osteoblasts), and ventricular myocytes; N-type (Non-L or Neuronal), P/Q-type (Purkinje and Granular), and R-type (dihydropyridine- Resistant) channels display longer-lasting conductance and are expressed throughout the nervous system; T-type (Transient) channels produce short-term conductance and are found in neurons and cells that have pacemaker activity [6]. The activation of the channels results in a $\mathrm{Ca}^{2+}$ cascade, which is associated with numerous host physiological functions including excitation-contraction-relaxation coupling of muscles, synaptic transmission, immunoprotection, etc.

Since 1984, it has been known that verapamil, the blocker of VGCCs, inhibits influenza A virus (IAV) infection [7]. Moreover, IAV infection induces $\mathrm{Ca}^{2+}$ influx, and the elevated intracellular $\mathrm{Ca}^{2+}$ promotes endocytic uptake of IAV [8]. Until recently, the underlying mechanism was revealed by Fujioka et al. [9]. They reported that several VGCC blockers and siRNA against the Ca 1.2 channel (L-type channel) inhibited H1N1 and H3N2 IAV infection in multiple cell lines. IAV attaches to the target cells by the viral hemagglutinin protein (HA), which is a type I transmembrane protein embedded in the viral envelope, binding to sialic acids [10]. Fujioka et al. showed that the virus HA binds to domain IV of $\mathrm{Ca}_{\mathrm{V}} 1.2$, which contains two potential sialylated asparagine residues (N1436 and N1487) $[9,11]$. When $\mathrm{Ca}_{V} 1.2$ mutants in one or both these residues were replaced with glutamine (N1436Q, N1487Q, and N1436Q + N1487Q), the interaction between HA and the Cav1.2 was attenuated compared with the wild-type fragment. They demonstrated that a VGCC blocker, diltiazem, significantly prolonged the survival of IAV-infected mice and allowed the recovery of the survivors. Therefore, Cav1.2 may serve as a host cell surface receptor that binds IAV and is critical for IAV entry (Figure 2A). New world hemorrhagic fever arenaviruses (NWA) are another virus that is reportedly sensitive to the VGCC blocker club member [12,13]. An siRNA screen with Junín virus glycoprotein-pseudotyped viruses identified that VGCCs are involved in NWA entry. Treatment with the channel blocker gabapentin, an FDA (U.S. Food and Drug Administration)-approved analgesic that targets the channel $\alpha 2 \delta 2$ subunit, protects against NWA infection [13]. This research work demonstrated that the interaction between a virus and VGCCs promotes virus entry at the virus-cell fusion step. 
A

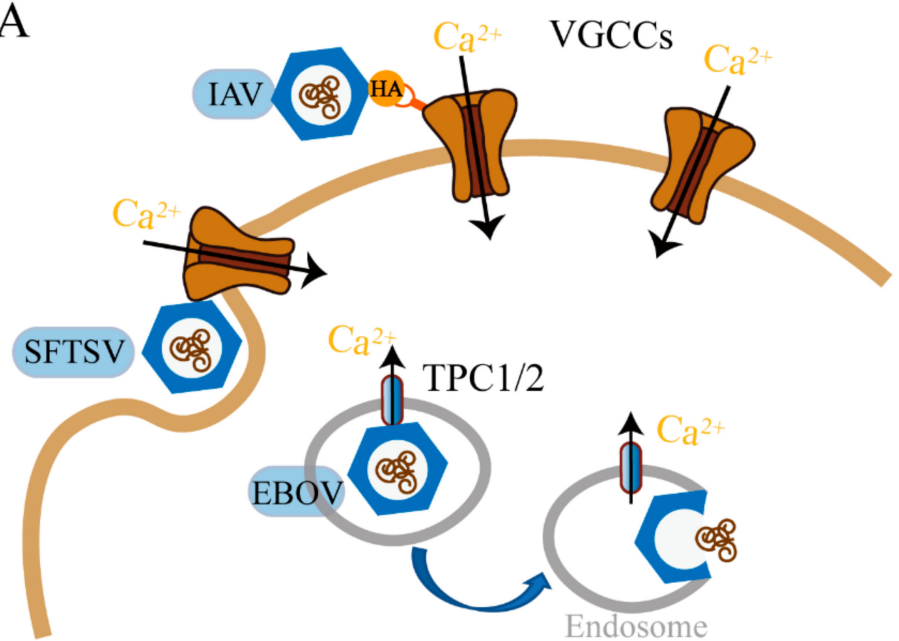

B

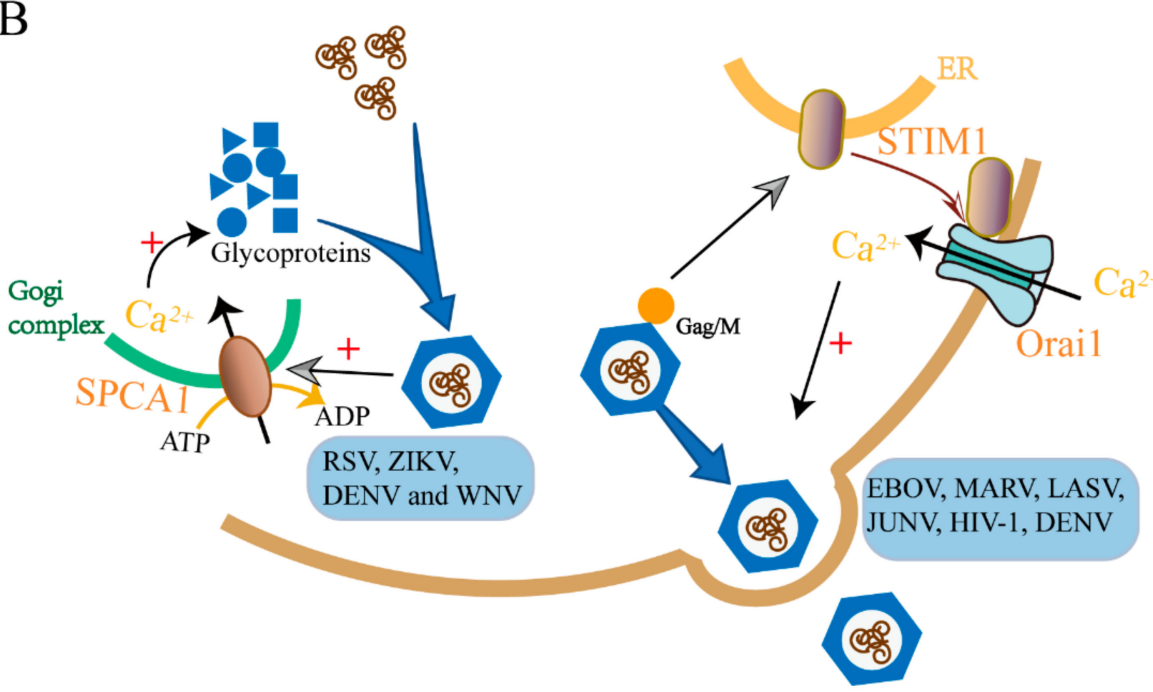

Figure 2. Examples of viruses interplaying with host calcium channels or pumps to achieve viral entry (A) and release (B). VGCCs are important for influenza A virus (IAV) and severe fever with thrombocytopenia syndrome virus (SFTSV) entry into the host cell as well as TPC1/2 for EBOV (A). RSV, Zika virus (ZIKA), dengue virus (DENV) and West Nile virus (WNV) hijack SPCA1 to facilitate their release as well as Ebola virus (EBOV), MARV, LASV, JUNV, HIV-1 and DENV manipulates STIM1/ORAI1 (B). For a complete list of definitions, see Table 1.

The effect on VGCCs is not only restricted to virus entry. A high-throughput screening of an FDA-approved drug library for inhibitors of Japanese encephalitis virus (JEV) identified five hit drugs, three of which are VGCCs blockers (manidipine, cilnidipine, and benidipine hydrochloride) [14]. Recombinant viral particles (RVPs) with the luciferase-reporting replicon were used to quantify the efficiency of JEV replication, which confirmed that these drugs inhibited JEV infection at the stage of replication. These drugs were subsequently validated for their antiviral activities against other flavivirus, such as Zika virus (ZIKV), dengue virus (DENV), and West Nile virus (WNV). Similarly, another research group screened the FDA-approved drug library and found that nifedipine and benidipine hydrochloride inhibited severe fever with thrombocytopenia syndrome virus (SFTSV) replication in vitro [12]. Moreover, the retrospective clinical investigation on SFTS patients showed that nifedipine can significantly inhibit SFTSV infection. These studies indicate that the VGCCs blockers are excellent candidates for broad-spectrum anti-virus treatment. Most of these FDA-approved VGCC blockers are clinically used to treat cardiovascular diseases. Similar to a double-edged sword, 
the cardiovascular effect of VGCC blockers may limit their antiviral application. Therefore, repurposing these drugs requires more analysis before clinical trials.

Further examples of virus-regulating VGCCs to service their replication can be found in HIV-1 and herpes simplex virus (HSV)-1. Two HIV-1 proteins, the membrane glycoprotein gp120 [15,16] and the transcriptical transactivator Tat $[17,18]$, have been identified to induce the elevation of host intracellular $\mathrm{Ca}^{2+}$ in various cell types, including neuronal, immune, and epithelial cells, via targeting the activity of VGCCs. The detailed information about the dysregulation of the L-type calcium channel by Tat can be found in the review $[16,17]$.

Taking together, the infections of viruses could increase the host's intracellular calcium to facilitate viral entry and replication by manipulating host VGCCs. In addition, herpes simplex virus (HSV)-1 could downregulate the VGCCs on infected neuronal cells to escape detection by host cells. T-type $\mathrm{Ca}^{2+}$ channels were reported as the targets of HSV-1 in sensory-like ND7-23 cells $[19,20]$. HSV-1 infection of differentiated ND7-23 cells causes a significant loss of T-type $\mathrm{Ca}^{2+}$ channels from the membrane, which depends on viral replication and protein synthesis. This downregulation of T-type $\mathrm{Ca}^{2+}$ channel expression may alter the ability of sensory neurons to transmit pain information. Thus, the lower expression of VGCCs may diminish the detection for viral infection by the host, which benefits virus survival and further infection.

Ebola virus (EBOV) used to be considered a VGCC blocker-sensitive virus, and several research groups independently reported that compounds blocking L-type channels (such as verapamil, nimodipine, and diltiazem) inhibited EBOV infection in vivo [21-23]. However, gabapentin, representing a fifth distinct class of L-type channel inhibitor, had no effect even at high concentrations. It has been shown that verapamil, nimodipine, and diltiazem also inhibit the activity of two-pore channels (TPCs) [24]. TPCs are intracellular voltage-gated and receptor-operated calcium permeable channels, playing an integral role in membrane trafficking pathways $[25,26]$. Mouse embryonic fibroblasts (MEFs) lacking TPC1 or TPC2 expression (Tpcn1 $1^{-/-}$, Tpcn2 $2^{-/-}$) resisted EBOV infection [27]. It turns out that the target of EBOV may not be classical L-type calcium channels but rather endosomal calcium channels termed TPCs (Figure 2A). The calcium channels inhibitors prevented virus-endosome membrane fusion and virus capsid releasing into the cell cytoplasm, which is a late entry step. EBOV acts on TPCs, which control the movement of endosomes containing virus particles, and thereby facilitate its intracellular trafficking $[27,28]$. The channel inhibitor, tetrandrine, significantly enhanced the survival of mice challenged with mouse-adapted EBOV without any detectable side effects. This indicates that tetrandrine is highly effective against EBOV disease in mice.

\section{Store-Operated Calcium (SOC) Channel in Viral Assembly and Egress}

SOC channels are the major $\mathrm{Ca}^{2+}$ entry pathways in non-excitable cells. The protein Orai1 on the plasma membrane and STIM1 (stromal interaction molecule) on ER are the molecular identities that are responsible for SOC channels activation. The depletion of ER $\mathrm{Ca}^{2+}$ stores promotes STIM1 proteins aggregation and interaction with Orai1 to open the channel, mediating $\mathrm{Ca}^{2+}$ entry $[29,30]$.

Most enveloped viruses are released extracellularly via exocytosis, also called budding, as an analogy of buds in plants [31,32]. The budding process of the enveloped viruses is triggered by a peptide motif (termed late (L) domains), which was discovered in the Gag polyproteins of retroviruses and $\mathrm{M}$ (matrix) proteins of rhabdoviruses [33]. These $\mathrm{L}$ domains interact with cellular proteins to promote the formation of virus vesicles that bud away from the cytoplasm [32,34]. Research works established that this essential final step of related viruses depends on the host $\mathrm{Ca}^{2+}$ signal mediated by SOC channels (STIM1/Orai1).

The research work done on four distinct hemorrhagic fever viruses (Ebolavirus (EBOV), Marburgvirus (MARV), Lassa Virus (LASV), and Junín Virus (JUNV)) demonstrated that EBOV, MARV VP40, and JUNV Z proteins trigger host cell $\mathrm{Ca}^{2+}$ signals by activating the ER $\mathrm{Ca}^{2+}$ sensing protein STIM1 and the plasma membrane ORAI1 channel. The STIM1/Orai1-mediated $\mathrm{Ca}^{2+}$ signal is critical for EBOV and related viruses budding from host cells [35]. The suppression of STIM1 expression 
and genetic inactivation or the pharmacological blockade of ORAI1 inhibits infections of EBOV, MARV, and JUNV in cultured cells (Figure 2B). Obviously, the matrix proteins or live virus activates STIM1 and the ORAI channel. Similarly to hemorrhagic fever viruses, the HIV-1 matrix protein Gag, directing HIV-1 budding, and mediating VLP (Virus-like Particle) formation also exhibit dependence on $\mathrm{Ca}^{2+}$ regulation $[36,37]$. Therefore, further study is needed to validate the role for STIM1 and the ORAI channel in HIV- 1 budding.

Infections of other enveloped RNA viruses that buds in similar mechanisms may also be inhibited by STIM1 and ORAI1 inhibitors. Indeed, SOC channel antagonists significantly reduced DENV yield [38]. When the human hepatic HepG2 and Huh-7 cells are infected by DENV, STIM1 and ORAI1 were shown to be co-localized in infected cells, indicating activation of the SOC channel $[38,39]$. Therefore, DENV infection alters cell $\mathrm{Ca}^{2+}$ homeostasis possibly via promoting the interaction between STIM1 and ORAI1.

It is possible that the viral proteins trigger the $\mathrm{Ca}^{2+}$ depletion in ER or prevent ER refilled with $\mathrm{Ca}^{2+}$ to maintain resting ER Ca ${ }^{2+}$ levels [40-42]. Alternately, these viral proteins may directly modify STIM1 and uncouple the activation of STIM1 from $\mathrm{Ca}^{2+}$ levels [35,43]. Thus, STIM1/ORAI might represent a conserved target to regulating the budding of enveloped RNA viruses and possibly DNA viruses that rely on similar host cellular proteins for budding. The example is that the hepatitis B virus $\mathrm{X}(\mathrm{HBx})$ protein upregulates the activity of the STIM1-ORAI1 channel complex [44]. The mechanisms by which these viruses activate STIM1 and ORAI1 represent novel therapeutic targets for controlling budding.

Calcium influx through the SOC channel also contributes to the elevated cytosolic calcium concentration induced by rotavirus (RV) infection. It has been well established that the dramatically increased cellular $\mathrm{Ca}^{2+}$ is the hallmark of rotavirus (RV) infection $[45,46]$. Rotavirus nonstructural protein 4 (NSP4) is an ER-localized viroporin that functionally depletes ER calcium. Thus, in rotavirus-infected cells, STIM1 is constitutively active and colocalizes with the ORAI1 channel. The knockdown of STIM1 or the pharmacological inhibition of SOC channels significantly reduced rotavirus yield, indicating that the SOC channel plays a critical role in the RV lifecycle [47,48].

\section{Host Transient Receptor Potential (TRP) Channels and Receptor-Operated Calcium (ROC) Channels}

\subsection{TRP Channels}

The TRP channel is a non-selective cation channel predominately permeable for $\mathrm{Ca}^{2+}[49,50]$. It is divided into six sub-families according to their amino acid sequence: TRP canonical or classical (TRPC), TRP vanilloid (TRPV), TRP melastatin (TRPM), TRP ankyrin (TRPA), TRP polycystin (TRPP), and TRP mucolipin (TRPML) [50]. They are ubiquitously expressed in different tissues and cell types and are a key player in the regulation of intracellular calcium. Nevertheless, reports about virus control TRP channels are not numerous.

TRPV4 mediates intracellular $\mathrm{Ca}^{2+}$ signals in response to several stimuli, including hypotonic cell swelling, mechanical forces, moderating heat, and UVB radiation [51]. When cells are exposed to the Zika virus or the purified viral envelope protein, TRPV4 mediates $\mathrm{Ca}^{2+}$ influx and drives the nuclear translocation of DEAD-box RNA helicase (DDX3X) [52]. DDX3X is an ATP-dependent RNA helicase from the DEAD-box helicase family and is involved in multiple stages of the RNA metabolism, from transcription to translation [53,54]. Moreover, diverse RNA viruses hijack DDX3X to multiply efficiently. Targeting TRPV4 reduces the infectivity of dengue, hepatitis C, and Zika viruses [52]. Overall, the research work demonstrated the role of TRPV4 in the regulation of DDX3X-dependent control of the RNA metabolism and viral infectivity [52].

The TRPV1, TRPA1, and TRPM8 channels are directly activated by chemical, thermal, and mechanical stimuli. They are potentially associated with respiratory virus-induced airway hypersensitivity [55]. The infection of respiratory viruses, such as respiratory syncytial virus (RSV), measles virus (MV), and human rhinovirus (HRV), was reported to increase the expression of these channels in sensory neurons and human bronchial epithelium cells $[56,57]$. The increase in TRPA1 and 
TRPV1 levels can be mediated by soluble factors induced by infection, whereas TRPM8 requires virus replication $[56,57]$. These reports may explain the possible mechanism by which respiratory viruses induce cough. Alternatively, the up-regulated TRP channels may be utilized by the respiratory viruses to create a favorable calcium environment. Further investigation is required to determine the possible pathway by which this happens.

\subsection{N-Methyl-D-Aspartate (NMDA) Receptors}

NMDArs and $\mathrm{IP}_{3}$ Rs are the two receptor-operated calcium (ROC) channels reported to be involved in virus-host interactions. NMDAr, which is activated by the endogenously synthesized excitant amino acid, glutamate, is widely expressed throughout the mammalian central nervous system and is particularly enriched in the cerebral cortex and hippocampus.

The Zika virus infection is a "neurodegenerative" disease. Costa and colleagues showed that blockage of the NMDAr channel activity with FDA-approved memantine or other antagonists prevents neuronal cell death and microgliosis induced by Zika in vitro and in vivo, without affecting the ability of Zika to replicate in the host [58,59]. It seems that NMDAr mainly contributes to Zika, triggering the neuronal cell death progress. Anyway, the blockade of NMDAr may be a viable treatment for patients at risk for Zika infection-induced neurodegeneration [59]. NMDAr blockade also significantly abrogated neuronal cell death and inflammatory response triggered by JEV infection [60]. Therefore, NMDAr are probably common attack targets of flavivirus, inducing host neuron cell death.

\section{3. $I P_{3}$ Receptors}

The engagement of receptors or agonist binding to the cell surface receptors activate phospholipase $\mathrm{C}$ (PLC), which hydrolyses phosphatidylinositol-4,5-biphosphate $\left(\mathrm{PIP}_{2}\right)$ to produce $\mathrm{IP}_{3}$. The activation of $\mathrm{IP}_{3} \mathrm{R}$ triggers $\mathrm{Ca}^{2+}$ release from stores and further increases $\mathrm{IP}_{3} \mathrm{R}^{\prime} \mathrm{s}$ sensitivity to $\mathrm{Ca}^{2+}$. Targeting $\mathrm{IP}_{3} \mathrm{Rs}$ is more universal among different virus types. In turn, this process generates a more profound effect on host cell physiology, including metabolic stress, neurotoxicity, and enterotoxicity. Modifying $\mathrm{IP}_{3}$ and directly interfering with $\mathrm{IP}_{3} \mathrm{R}$ are the main ways in which viruses affect calcium release through $\mathrm{IP}_{3} \mathrm{R}$. For example, human cytomegalovirus (HCMV) UL37x1 protein interacts with the host P2Y2 purinergic receptor to increase intracellular $\mathrm{Ca}^{2+}$ levels via the $\mathrm{PLC}-\mathrm{IP}_{3}$ pathway, and this activity is important to viral replication [61]. HIV-1 Gp120 and Tat upregulate intracellular $\mathrm{IP}_{3}$ [37,62], while HIV Nef $[63,64]$ and p12(I) human T-cell lymphotropic virus type 1 (HTLV-1) [65] activate $\mathrm{IP}_{3} \mathrm{R}$ directly as an agonist. Glycoprotein E of HSV redistributes the density of $\mathrm{IP}_{3} \mathrm{Rs}$ within infected cells [66]. Some virus proteins activate $\mathrm{IP}_{3} \mathrm{R}$ through both ways. Enterotoxin NSP4 of RV and HCMV UL37x1-encoded protein increases the basal permeability of the $E R$ as $\mathrm{IP}_{3}$ diffuses and binds to $\mathrm{IP}_{3} \mathrm{Rs}$ to stimulate $\mathrm{Ca}^{2+}$ release. These virus proteins deplete $\mathrm{ER} \mathrm{Ca}^{2+}$ storage during early stages of viral infection to increase the replication ability of viruses. On the other hand, the depletion of ER calcium storage triggers the calcium influx through SOCs (STIM1/ORAI1).

\section{Calcium Pumps}

The calcium pumps $\left(\mathrm{Ca}^{2+}\right.$ ATPase) and the $\mathrm{Na}^{+}-\mathrm{Ca}^{2+}$ exchanger are the main regulators of intracellular $\mathrm{Ca}^{2+}$ concentrations [67]. Three $\mathrm{Ca}^{2+}$ ATPase types (pumps) have been described in animal cells located in the membranes of the sarcoplasmic reticulum (SERCA pump), in those of the Golgi network (Secretory Pathway $\mathrm{Ca}^{2+}$ ATPase, SPCA pump), and in the plasma membrane (PMCA pump) [68]. At the end of a stimulus, these pumps participate in returning the cell to its resting state by the decrease in the cytosolic $\mathrm{Ca}^{2+}$ concentration. For example, SERCA transports $\mathrm{Ca}^{2+}$ from the cytoplasm into the lumen of the ER. PMCA pumps function to remove $\mathrm{Ca}^{2+}$ from the cell. They serve as the main regulators of intracellular and extracellular $\mathrm{Ca}^{2+}$ concentrations. All three calcium pumps are reported to be involved in different viral lifecycles.

Maturation is the last assembly step of a virus particle. In this step, the virus acquires the infectivity, which is essential for its lifecycle. The results obtained from a genome-wide knockout screen indicated 
that SPCA1 in the Golgi network is critical for human respiratory syncytial virus (RSV) infection [69-71]. Further study demonstrated that similar to RSV, other viruses from the Paramyxoviridae, Flaviviridae, and Togaviridae families also failed to spread in SPCA1-deficient cells. Studies on this mechanism revealed that $\mathrm{Ca}^{2+}$ pumped into Golgi by SPCA1 is the trigger to produce normal functional viral glycoproteins that are essential for virus spread. Therefore, SPCA1 may be a promising target for therapeutic intervention against a diverse set of viruses (Figure 2B). However, in this study, herpes simplex 1 (HSV-1), vesicular stomatitis (VSV), bunyamwera (BUNV), and LCMV were unaffected by the loss of SPCA1. That is probably because the maturation of these viral glycoproteins requires different triggers.

Cui et al. [72] screened the natural product library and found that cyclopiazonic acid, an inhibitor of SERCA, was shown to have activity in the low micromolar range against RSV strains at the step of virus genome replication. Further study found that another SERCA inhibitor BHQ had a similar effect [72]. It is probable that SERCA inhibitors prevent cytosolic calcium returning to the ER from the cytosol via SERCA, resulting in an increase in intracellular calcium concentration. A continuous higher concentration of intracellular calcium may impair viral genome replication and/or transcription, thereby reducing virus yield.

\section{Conclusions}

The journey of viral infections is also a procedure during which a virus grabs the host intracellular calcium signaling system and homeostasis to benefit its own lifecycle. The disturbance of the host $\mathrm{Ca}^{2+}$ system by virus may suppress T-cell responsiveness, antiapoptotic, and other protentional functions. In this review, we summarized the calcium permeable channels and calcium pumps located on host cell membranes that may be potential therapeutic targets for viral infections (Table 1). However, the calcium channel family is continuously being refreshed with the discovery of new members, and the effect of viruses on the host intracellular calcium environment is not often achieved through a single pathway; it is more complicated. Both upstream messengers and downstream $\mathrm{Ca}^{2+}$ binding proteins are targets for pharmacological intervention. Thus, explicating the entire picture of all aspects of the calcium-virus interplay at the molecular level will be a challenge in the future.

The prevention of and therapeutic efforts against virus infections are often challenged by the high mutation rates of viral proteins. However, those host calcium apparatus proteins required by viral replication and transmission are highly conserved, essentially immutable, and thus are potentially an Achilles' heel of virus infection. As described above, almost all the calcium permeable channels or calcium pumps are possible attack targets of viruses and customized host intracellular calcium signaling via effects on these channel proteins. Targeting those host cellular proteins required by virus infection may be one treatment strategy with therapeutic potential, which may avoid or delay the development of resistance. The identified calcium-permeable proteins discussed above offer suitable target proteins for inhibiting virus infection. VGCCs and NMDA receptors are two of most well studied targets because of the availability of specific channel antagonists. Moreover, some of those compounds are FDA-approved drugs with clinical application. For example, verapamil, amlodipine, verapamil, and diltiazem, which are widely used to treat cardiovascular disease, have shown inhibition for various virus infection. Memantine, which is an FDA-approved Alzheimer's drug, reduces neurological complications associated with Zika virus infection. Obviously, this direction depends on the identification of selective and potent small molecule modulators of calcium channels. Currently, aside from some blockers for VGCCs and the NMDA receptor, almost no other channel modulators can be used in clinics, although important progress has been made in recent years toward high quality and widely available channel modulators. Furthermore, modulators should be generated with properties that make them suitable for in vivo use. This review outlines promising progress made with the potentiation for a host cell calcium channels modulator to become an antiviral drug. We believe that modulators for host calcium channels are the pots of gold for antiviral drug development. 
Table 1. Calcium channels/pumps utilized by a virus

\begin{tabular}{|c|c|c|}
\hline Cellular Targets & Virus & Consequences [Ref.] \\
\hline \multirow{6}{*}{ VGCCs } & IAV & CaV1.2 serves as a host cell surface receptor that binds IAV and is critical for IAV entry [9]. \\
\hline & SFTSV & $\begin{array}{c}\text { Benidipine hydrochloride, VGCC blocker, inhibits SFTSV infection via impairing virus } \\
\text { internalization and genome replication [12]. }\end{array}$ \\
\hline & NWV & Virus binds to VGCCs and promotes virus entry at the virus-cell fusion step [13]. \\
\hline & Flavivirus (JEV, ZIKV, DENV, and WNV & $\begin{array}{l}\text { VGCCs blockers inhibit flavivirus (JEV, ZIKV, DENV and WNV) infection at the stage of } \\
\text { replication [14]. }\end{array}$ \\
\hline & HIV-1 & Tat/gp120 overactivate VGCCs [15-17]. \\
\hline & HSV-1 & $\begin{array}{l}\text { HSV-1 downregulates the Cav } 3.2 \text { channel and diminishes the detection of viral infection by } \\
\text { host }[19,20] .\end{array}$ \\
\hline TPCs & EBOV & $\begin{array}{l}\text { Facilitates virus-endosome membrane fusion and releases of virus capsid into the cell } \\
\text { cytoplasm [27]. }\end{array}$ \\
\hline STIM1/ORAI1 & EBOV, MARV, LASV, JUNV, HIV-1, DENV, and HBV & Promote virion assembly and budding $[35-38,44]$. \\
\hline TRPV4 & ZIKV & Activation of TRPV4- releases DDX3X and promote the viral RNA metabolism [52]. \\
\hline \multirow{2}{*}{ NMDAr } & ZIKV, JEV & NMDAr contributes to ZIKA by triggering the neuronal cell death progress $[58,60]$. \\
\hline & HIV-1 & Increases $\mathrm{Ca}^{2+}$ influx [62]. \\
\hline $\mathrm{IP}_{3} \mathrm{R}$ & HIV-1, HSV, HRV, and HCMV & $\begin{array}{l}\text { These viral proteins deplete ER } \mathrm{Ca}^{2+} \text { store during early stages of viral infection to increase } \\
\text { the replication ability of viruses }[37,62-64,66] .\end{array}$ \\
\hline SPCA1 & RSV, ZIKV, DENV and WNV & Trigger to produce functional viral glycoproteins that are essential for virus spread [70] \\
\hline $\begin{array}{l}\text { Abbreviations: } \\
\text { (JEV), Zika vir } \\
\text { (JUNV), Hepat } \\
\text { channels (TPC } \\
\text { pathway } \mathrm{Ca}^{2+}\end{array}$ & $\begin{array}{l}\text { za A virus (IAV), Severe fever with thrombocytopenia } \\
\text { V), Dengue virus (DENV), West Nile virus (WNV), He } \\
\text { us (HBV), Respiratory syncytial virus (RSV), Human rh } \\
\text { nal interaction molecule } 1 \text { (STIM1), Transient receptor } \\
\text { (SPCA1). DEAD-box RNA helicase (DDX3X), Endopla }\end{array}$ & $\begin{array}{l}\text { me virus (SFTSV), New world hemorrhagic fever arenaviruses (NWV), Japanese encephalitis virus } \\
\text { nplex virus (HSV)-1, Ebolavirus (EBOV), Marburgvirus (MARV), Lassa Virus (LASV), Junín Virus } \\
\text { (HRV), and Human cytomegalovirus (HCMV). Voltage-gated calcium channels (VGCCs), Two-pore } \\
\left.\text { ial vanilloid } 4 \text { (TRPV4), N-methyl-D-aspartate receptor (NMDAR), IP } P_{3} \text { receptor (IP }{ }_{3} R\right) \text {, Secretory } \\
\text { ticulum (ER). }\end{array}$ \\
\hline
\end{tabular}


Author Contributions: X.C. and W.Z. conceived this article; X.C. and R.C. wrote the original draft and prepared figures; R.C. and W.Z. edited and reviewed the manuscript. All authors have read and agreed to the published version of the manuscript.

Funding: This work was funded by the National Natural Science Foundation of China, grant numbers 81773631 and 81900402), National Science and Technology Major Projects, grant number 2018ZX09711003 and Fundamental Research Funds for the Central Universities grant number G2019KY0501.

Conflicts of Interest: The authors declare no conflict of interest.

\section{References}

1. Martinez de Victoria, E. Calcium, essential for health. Nutr. Hosp. 2016, 33 (Suppl. S4), 341.

2. Berridge, M.J.; Bootman, M.D.; Lipp, P. Calcium-A life and death signal. Nature 1998, 395, 645-648. [CrossRef] [PubMed]

3. Olivier, M. Modulation of host cell intracellular $\mathrm{Ca}^{2+}$. Parasitol. Today 1996, 12, 145-150. [CrossRef]

4. Clark, K.B.; Eisenstein, E.M. Targeting host store-operated $\mathrm{Ca}^{2+}$ release to attenuate viral infections. Curr. Top. Med. Chem. 2013, 13, 1916-1932. [CrossRef] [PubMed]

5. Gonzales-van Horn, S.R.; Sarnow, P. Making the Mark: The Role of Adenosine Modifications in the Life Cycle of RNA Viruses. Cell Host Microbe 2017, 21, 661-669. [CrossRef] [PubMed]

6. Atlas, D. Voltage-gated calcium channels function as $\mathrm{Ca}^{2+}$-activated signaling receptors. Trends Biochem. Sci. 2014, 39, 45-52. [CrossRef] [PubMed]

7. Nugent, K.M.; Shanley, J.D. Verapamil inhibits influenza A virus replication. Arch. Virol. 1984, 81, $163-170$. [CrossRef]

8. Fujioka, Y.; Tsuda, M.; Nanbo, A.; Hattori, T.; Sasaki, J.; Sasaki, T.; Miyazaki, T.; Ohba, Y. A Ca ${ }^{2+}$-dependent signalling circuit regulates influenza a virus internalization and infection. Nat. Commun. 2013, 4, 2763. [CrossRef]

9. Fujioka, Y.; Nishide, S.; Ose, T.; Suzuki, T.; Kato, I.; Fukuhara, H.; Fujioka, M.; Horiuchi, K.; Satoh, A.O.; Nepal, P. A Sialylated Voltage-Dependent $\mathrm{Ca}^{2+}$ Channel Binds Hemagglutinin and Mediates Influenza A Virus Entry into Mammalian Cells. Cell Host Microbe 2018, 23, 809-818. [CrossRef]

10. Chandrasekaran, A.; Srinivasan, A.; Raman, R.; Viswanathan, K.; Raguram, S.; Tumpey, T.M.; Sasisekharan, V.; Sasisekharan, R. Glycan topology determines human adaptation of avian H5N1 virus hemagglutinin. Nat. Biotechnol. 2008, 26, 107-113. [CrossRef]

11. Lazniewska, J.; Weiss, N. Glycosylation of voltage-gated calcium channels in health and disease. Biochim. Biophys. Acta Biomembr. 2017, 1859, 662-668. [CrossRef] [PubMed]

12. Li, H.; Zhang, L.K.; Li, S.F.; Zhang, S.F.; Wan, W.W.; Zhang, Y.L.; Xin, Q.L.; Dai, K.; Hu, Y.Y.; Wang, Z.B. Calcium channel blockers reduce severe fever with thrombocytopenia syndrome virus (SFTSV) related fatality. Cell Res. 2019, 29, 739-753. [CrossRef] [PubMed]

13. Lavanya, M.; Cuevas, C.D.; Thomas, M.; Cherry, S.; Ross, S.R. siRNA screen for genes that affect Junin virus entry uncovers voltage-gated calcium channels as a therapeutic target. Sci. Transl. Med. 2013, 5, 204 ra131. [CrossRef] [PubMed]

14. Wang, S.; Liu, Y.; Guo, J.; Wang, P.; Zhang, L.; Xiao, G.; Wang, W. Screening of FDA-Approved Drugs for Inhibitors of Japanese Encephalitis Virus Infection. J. Virol. 2017, 91, e01055-17. [CrossRef]

15. Dreyer, E.B.; Kaiser, P.K.; Offermann, J.T.; Lipton, S.A. HIV-1 coat protein neurotoxicity prevented by calcium channel antagonists. Science 1990, 248, 364-367. [CrossRef]

16. Haughey, N.J.; Mattson, M.P. Calcium dysregulation and neuronal apoptosis by the HIV-1 proteins Tat and gp120. J. Acquir. Immune. Defic. Syndr. 2002, 31 (Suppl. S2), S55-S61. [CrossRef]

17. Hu, X.T. HIV-1 Tat-Mediated Calcium Dysregulation and Neuronal Dysfunction in Vulnerable Brain Regions. Curr. Drug Targets 2016, 17, 4-14. [CrossRef]

18. Kruman, I.I.; Nath, A.; Mattson, M.P. HIV-1 protein Tat induces apoptosis of hippocampal neurons by a mechanism involving caspase activation, calcium overload, and oxidative stress. Exp. Neurol. 1998, 154, $276-288$. [CrossRef]

19. Zhang, Q.; Hsia, S.C.; Martin-Caraballo, M. Regulation of T-type Ca ${ }^{2+}$ channel expression by herpes simplex virus-1 infection in sensory-like ND7 cells. J. Neurovirol. 2017, 23, 657-670. [CrossRef] 
20. Zhang, Q.; Hsia, S.C.; Martin-Caraballo, M. Regulation of T-type $\mathrm{Ca}^{2+}$ channel expression by interleukin-6 in sensory-like ND7/23 cells post-herpes simplex virus (HSV-1) infection. J. Neurochem. 2019, 151, 238-254. [CrossRef]

21. Kolokoltsov, A.A.; Saeed, M.F.; Freiberg, A.N.; Holbrook, M.R.; Davey, R.A. Identification of novel cellular targets for therapeutic intervention against Ebola virus infection by siRNA screening. Drug Dev. Res. 2009, 70, 255-265. [CrossRef] [PubMed]

22. Gehring, G.; Rohrmann, K.; Atenchong, N.; Mittler, E.; Becker, S.; Dahlmann, F.; Pohlmann, S.; Vondran, F.W.; David, S.; Manns, M.P. The clinically approved drugs amiodarone, dronedarone and verapamil inhibit filovirus cell entry. J. Antimicrob. Chemother. 2014, 69, 2123-2131. [CrossRef] [PubMed]

23. Madrid, P.B.; Chopra, S.; Manger, I.D.; Gilfillan, L.; Keepers, T.R.; Shurtleff, A.C.; Green, C.E.; Iyer, L.V.; Dilks, H.H.; Davey, R.A. A systematic screen of FDA-approved drugs for inhibitors of biological threat agents. PLoS ONE 2013, 8, e60579. [CrossRef] [PubMed]

24. Calcraft, P.J.; Ruas, M.; Pan, Z.; Cheng, X.; Arredouani, A.; Hao, X.; Tang, J.; Rietdorf, K.; Teboul, L.; Chuang, K.T. NAADP mobilizes calcium from acidic organelles through two-pore channels. Nature 2009, 459, 596-600. [CrossRef] [PubMed]

25. Zhu, M.X.; Ma, J.; Parrington, J.; Calcraft, P.J.; Galione, A.; Evans, A.M. Calcium signaling via two-pore channels: Local or global, that is the question. Am. J. Physiol. Cell Physiol. 2010, 298, C430-C441. [CrossRef] [PubMed]

26. Morgan, A.J. $\mathrm{Ca}^{2+}$ dialogue between acidic vesicles and ER. Biochem. Soc. Trans. 2016, 44, 546-553. [CrossRef] [PubMed]

27. Sakurai, Y.; Kolokoltsov, A.A.; Chen, C.C.; Tidwell, M.W.; Bauta, W.E.; Klugbauer, N.; Grimm, C.; Wahl-Schott, C.; Biel, M.; Davey, R.A. Two-pore channels control Ebola virus host cell entry and are drug targets for disease treatment. Science 2015, 347, 995-998. [CrossRef]

28. Kintzer, A.F.; Stroud, R.M. Structure, inhibition and regulation of two-pore channel TPC1 from Arabidopsis thaliana. Nature 2016, 531, 258-262. [CrossRef]

29. Hogan, P.G.; Lewis, R.S.; Rao, A. Molecular basis of calcium signaling in lymphocytes: STIM and ORAI. Annu. Rev. Immunol. 2010, 28, 491-533. [CrossRef]

30. Nwokonko, R.M.; Cai, X.; Loktionova, N.A.; Wang, Y.; Zhou, Y.; Gill, D.L. The STIM-Orai Pathway: Conformational Coupling between STIM and Orai in the Activation of Store-Operated $\mathrm{Ca}^{2+}$ Entry. Adv. Exp. Med. Biol. 2017, 993, 83-98.

31. Sepulveda, C.S.; Garcia, C.C.; Damonte, E.B. Determining the Virus Life-Cycle Stage Blocked by an Antiviral. Methods Mol. Biol. 2018, 1604, 371-392. [PubMed]

32. Hartlieb, B.; Weissenhorn, W. Filovirus assembly and budding. Virology 2006, 344, 64-70. [CrossRef] [PubMed]

33. Chen, B.J.; Lamb, R.A. Mechanisms for enveloped virus budding: Can some viruses do without an ESCRT? Virology 2008, 372, 221-232. [CrossRef] [PubMed]

34. Licata, J.M.; Simpson-Holley, M.; Wright, N.T.; Han, Z.; Paragas, J.; Harty, R.N. Overlapping motifs (PTAP and PPEY) within the Ebola virus VP40 protein function independently as late budding domains: Involvement of host proteins TSG101 and VPS-4. J. Virol. 2003, 77, 1812-1819. [CrossRef]

35. Han, Z.; Madara, J.J.; Herbert, A.; Prugar, L.I.; Ruthel, G.; Lu, J.; Liu, Y.; Liu, W.; Liu, X.; Wrobel, J.E. Calcium Regulation of Hemorrhagic Fever Virus Budding: Mechanistic Implications for Host-Oriented Therapeutic Intervention. PLoS Pathog. 2015, 11, e1005220. [CrossRef]

36. Ehrlich, L.S.; Carter, C.A. HIV Assembly and Budding: $\mathrm{Ca}^{2+}$ Signaling and Non-ESCRT Proteins Set the Stage. Mol. Biol. Int. 2012, 2012, 851670. [CrossRef]

37. Ehrlich, L.S.; Medina, G.N.; Carter, C.A. ESCRT machinery potentiates HIV-1 utilization of the PI $(4,5)$ P (2)-PLC-IP3R-Ca ${ }^{2+}$ signaling cascade. J. Mol. Biol. 2011, 413, 347-358. [CrossRef]

38. Dionicio, C.L.; Pena, F.; Constantino-Jonapa, L.A.; Vazquez, C.; Yocupicio-Monroy, M.; Rosales, R.; Zambrano, J.L.; Ruiz, M.C.; Del Angel, R.M.; Ludert, J.E. Dengue virus induced changes in $\mathrm{Ca}^{2+}$ homeostasis in human hepatic cells that favor the viral replicative cycle. Virus Res. 2018, 245, 17-28. [CrossRef]

39. Cheshenko, N.; Liu, W.; Satlin, L.M.; Herold, B.C. Multiple receptor interactions trigger release of membrane and intracellular calcium stores critical for herpes simplex virus entry. Mol. Biol. Cell 2007, 18, 3119-3130. [CrossRef] 
40. Robinson, L.C.; Marchant, J.S. Enhanced $\mathrm{Ca}^{2+}$ leak from ER Ca ${ }^{2+}$ stores induced by hepatitis C NS5A protein. Biochem. Biophys. Res. Commun. 2008, 368, 593-599. [CrossRef]

41. Zhadina, M.; Bieniasz, P.D. Functional interchangeability of late domains, late domain cofactors and ubiquitin in viral budding. PLoS Pathog. 2010, 6, e1001153. [CrossRef] [PubMed]

42. Ruiz, M.C.; Aristimuno, O.C.; Diaz, Y.; Pena, F.; Chemello, M.E.; Rojas, H.; Ludert, J.E.; Michelangeli, F. Intracellular disassembly of infectious rotavirus particles by depletion of $\mathrm{Ca}^{2+}$ sequestered in the endoplasmic reticulum at the end of virus cycle. Virus Res. 2007, 130, 140-150. [CrossRef] [PubMed]

43. Freedman, B.D.; Harty, R.N. Calcium and filoviruses: A budding relationship. Future Microbiol. 2016, 11, 713-715. [CrossRef] [PubMed]

44. Yao, J.H.; Liu, Z.J.; Yi, J.H.; Wang, J.; Liu, Y.N. Hepatitis B Virus X Protein Upregulates Intracellular Calcium Signaling by Binding C-terminal of Orail Protein. Curr. Med. Sci. 2018, 38, 26-34. [CrossRef]

45. Michelangeli, F.; Ruiz, M.C.; del Castillo, J.R.; Ludert, J.E.; Liprandi, F. Effect of rotavirus infection on intracellular calcium homeostasis in cultured cells. Virology 1991, 181, 520-527. [CrossRef]

46. Pham, T.; Perry, J.L.; Dosey, T.L.; Delcour, A.H.; Hyser, J.M. The Rotavirus NSP4 Viroporin Domain is a Calcium-conducting Ion Channel. Sci. Rep. 2017, 7, 43487. [CrossRef]

47. Hyser, J.M.; Utama, B.; Crawford, S.E.; Broughman, J.R.; Estes, M.K. Activation of the endoplasmic reticulum calcium sensor STIM1 and store-operated calcium entry by rotavirus requires NSP4 viroporin activity. J. Virol. 2013, 87, 13579-13588. [CrossRef]

48. Chang-Graham, A.L.; Perry, J.L.; Strtak, A.C.; Ramachandran, N.K.; Criglar, J.M.; Philip, A.A.; Patton, J.T.; Estes, M.K.; Hyser, J.M. Rotavirus Calcium Dysregulation Manifests as Dynamic Calcium Signaling in the Cytoplasm and Endoplasmic Reticulum. Sci. Rep. 2019, 9, 10822. [CrossRef]

49. Li, J.; Zhang, X.; Song, X.; Liu, R.; Zhang, J.; Li, Z. The structure of TRPC ion channels. Cell Calcium. 2019, 80, 25-28. [CrossRef]

50. Hicks, G.A. TRP channels as therapeutic targets: Hot property, or time to cool down? Neurogastroenterol. Motil. 2006, 18, 590-594. [CrossRef]

51. Garcia-Elias, A.; Mrkonjic, S.; Jung, C.; Pardo-Pastor, C.; Vicente, R.; Valverde, M.A. The TRPV4 channel. Handb. Exp. Pharm. 2014, 222, 293-319.

52. Donate-Macian, P.; Jungfleisch, J.; Perez-Vilaro, G.; Rubio-Moscardo, F.; Peralvarez-Marin, A.; Diez, J.; Valverde, M.A. The TRPV4 channel links calcium influx to DDX3X activity and viral infectivity. Nat. Commun. 2018, 9, 2307. [CrossRef] [PubMed]

53. Ariumi, Y. Multiple functions of DDX3 RNA helicase in gene regulation, tumorigenesis, and viral infection. Front. Genet. 2014, 5, 423. [CrossRef] [PubMed]

54. Valiente-Echeverria, F.; Hermoso, M.A.; Soto-Rifo, R. RNA helicase DDX3: At the crossroad of viral replication and antiviral immunity. Rev. Med. Virol. 2015, 25, 286-299. [CrossRef]

55. Fujita, T.; Liu, Y.; Higashitsuji, H.; Itoh, K.; Shibasaki, K.; Fujita, J.; Nishiyama, H. Involvement of TRPV3 and TRPM8 ion channel proteins in induction of mammalian cold-inducible proteins. Biochem. Biophys. Res. Commun. 2018, 495, 935-940. [CrossRef]

56. Omar, S.; Clarke, R.; Abdullah, H.; Brady, C.; Corry, J.; Winter, H.; Touzelet, O.; Power, U.F.; Lundy, F.; McGarvey, L.P. Respiratory virus infection up-regulates TRPV1, TRPA1 and ASICS3 receptors on airway cells. PLoS ONE 2017, 12, e0171681. [CrossRef]

57. Abdullah, H.; Heaney, L.G.; Cosby, S.L.; McGarvey, L.P. Rhinovirus upregulates transient receptor potential channels in a human neuronal cell line: Implications for respiratory virus-induced cough reflex sensitivity. Thorax 2014, 69, 46-54. [CrossRef]

58. Costa, V.V.; Del Sarto, J.L.; Rocha, R.F.; Silva, F.R.; Doria, J.G.; Olmo, I.G.; Marques, R.E.; Queiroz-Junior, C.M.; Foureaux, G.; Araujo, J.M.S. N-Methyl-d-Aspartate (NMDA) Receptor Blockade Prevents Neuronal Death Induced by Zika Virus Infection. MBio 2017, 8, e00543-17. [CrossRef]

59. Sirohi, D.; Kuhn, R.J. Can an FDA-Approved Alzheimer's Drug Be Repurposed for Alleviating Neuronal Symptoms of Zika Virus? MBio 2017, 8, e00916-17. [CrossRef]

60. Chen, Z.; Wang, X.; Ashraf, U.; Zheng, B.; Ye, J.; Zhou, D.; Zhang, H.; Song, Y.; Chen, H.; Zhao, S. Activation of neuronal N-methyl-D-aspartate receptor plays a pivotal role in Japanese encephalitis virus-induced neuronal cell damage. J. Neuroinflammation 2018, 15, 238. [CrossRef] 
61. Chen, S.; Shenk, T.; Nogalski, M.T. P2Y2 purinergic receptor modulates virus yield, calcium homeostasis, and cell motility in human cytomegalovirus-infected cells. Proc. Natl. Acad. Sci. USA 2019, 116, 18971-18982. [CrossRef] [PubMed]

62. Ehrlich, L.S.; Medina, G.N.; Photiadis, S.; Whittredge, P.B.; Watanabe, S.; Taraska, J.W.; Carter, C.A. Tsg101 regulates PI $(4,5) \mathrm{P} 2 / \mathrm{Ca}^{2+}$ signaling for HIV-1 Gag assembly. Front. Microbiol. 2014, 5, 234. [CrossRef] [PubMed]

63. Ehrlich, L.S.; Medina, G.N.; Khan, M.B.; Powell, M.D.; Mikoshiba, K.; Carter, C.A. Activation of the inositol (1,4,5)-triphosphate calcium gate receptor is required for HIV-1 Gag release. J. Virol. 2010, 84, 6438-6451. [CrossRef] [PubMed]

64. Manninen, A.; Saksela, K. HIV-1 Nef interacts with inositol trisphosphate receptor to activate calcium signaling in T cells. J. Exp. Med. 2002, 195, 1023-1032. [CrossRef]

65. Ding, W.; Albrecht, B.; Kelley, R.E.; Muthusamy, N.; Kim, S.J.; Altschuld, R.A.; Lairmore, M.D. Human T-cell lymphotropic virus type 1 p12 (I) expression increases cytoplasmic calcium to enhance the activation of nuclear factor of activated T cells. J. Virol. 2002, 76, 10374-10382. [CrossRef]

66. Cheshenko, N.; Del Rosario, B.; Woda, C.; Marcellino, D.; Satlin, L.M.; Herold, B.C. Herpes simplex virus triggers activation of calcium-signaling pathways. J. Cell Biol. 2003, 163, 283-293. [CrossRef]

67. Strehler, E.E.; Zacharias, D.A. Role of alternative splicing in generating isoform diversity among plasma membrane calcium pumps. Physiol. Rev. 2001, 81, 21-50. [CrossRef]

68. Brini, M.; Cali, T.; Ottolini, D.; Carafoli, E. Calcium pumps: Why so many? Compr. Physiol. 2012, 2, $1045-1060$.

69. Griffiths, C.; Drews, S.J.; Marchant, D.J. Respiratory Syncytial Virus: Infection, Detection, and New Options for Prevention and Treatment. Clin. Microbiol. Rev. 2017, 30, 277-319. [CrossRef]

70. Hoffmann, H.H.; Schneider, W.M.; Blomen, V.A.; Scull, M.A.; Hovnanian, A.; Brummelkamp, T.R.; Rice, C.M. Diverse Viruses Require the Calcium Transporter SPCA1 for Maturation and Spread. Cell Host Microbe 2017, 22, 460-470. [CrossRef]

71. Cervantes-Ortiz, S.L.; Zamorano Cuervo, N.; Grandvaux, N. Respiratory Syncytial Virus and Cellular Stress Responses: Impact on Replication and Physiopathology. Viruses 2016, 8, 124. [CrossRef] [PubMed]

72. Cui, R.; Wang, Y.; Wang, L.; Li, G.; Lan, K.; Altmeyer, R.; Zou, G. Cyclopiazonic acid, an inhibitor of calcium-dependent ATPases with antiviral activity against human respiratory syncytial virus. Antivir. Res. 2016, 132, 38-45. [CrossRef] [PubMed] 